\title{
Tantangan Dalam Implementasi Model Integrasi Industri Perkapalan Di Indonesia
}

\author{
Mohammad Rizal Firmansyah*, Wihdat Djafar \\ Department Teknik Perkapalan, Fakultas Teknik, Universitas Hasanuddin \\ Jl. Perintis Kemerdekaan Km. 10 Tamalanrea - Makassar 90245 \\ * Korespondensi penulis, surel: mr.firmansyah@unhas.ac.id
}

\begin{abstract}
Indonesian shipbuilding Industry plays significant roles in supporting the economics of the country in the utilization of sea resources, the distribution of natural resources as well as interconnecting people between islands. Hence, it is significant for this industry to survive and keep growing and being competitive not only to fulfill the domestic need on ships but also for export to overseas. Support from the Indonesian government with the policy to build all ships which are operated domestically in the Indonesian shipyards is needed. In the global level, the individual shipyard is relatively difficult to compete with the overseas shipyard. This is because the current global competition is not between individual shipyards but between collaboration shipyards. One of the reasons is there is no collaboration model between shipyards which appropriate with the condition of Indonesian shipyards herself can be found in the literature. This paper discusses an integration model for 4 Indonesian BUMN shipyards which is based on the domestic shipyards characteristics and challenges faced in the implementation stages.
\end{abstract}

Keywords: Indonesian shipbuilding industry, collaboration, shipyard

\begin{abstract}
Abstrak
Industri perkapalan Indonesia mempunyai peran penting dalam mendukung peningkatan ekonomi negara berkaitan dengan pemanfaatan sumber daya laut, penyebaran hasil hasil sumber daya di darat dan laut serta interkoneksi masyarakat antara satu pulau dan pulau lainnya. Karenanya sangat penting bagi industri ini untuk bertahan, terus tumbuh dan kompetitif bukan hanya dalam memenuhi kebutuhan kapal domestik tetapi juga untuk kebutuhan ekspor. Dukungan pemerintah dengan berbagai kebijakannya untuk mewujudkan ketahanan kapal untuk kebutuhan dalam negeri ini sangat dibutuhkan sehingga kita tidak perlu lagi mengimpor kapal yang akan beroperasi di wilayah perairan Indonesia. Dalam tataran global, individual galangan dalam negeri relatif masih sulit untuk bersaing dengan galangan kapal luar negeri karena pola persaingan global sekarang ini bukan lagi antar galangan tetapi antar kolaborasi galangan kapal. Salah satu yang menjadi penyebabnya adalah belum adanya model kolaborasi antar galangan kapal yang sesuai dengan kondisi galangan kapal Indonesia itu sendiri. Paper ini mendiskusikan sebuah model awal integrasi 4 galangan kapal BUMN Indonesia yang didasarkan pada karakteristik galangan kapal dalam negeri dan tantangan yang dihadapi dalam proses implementasi model itu di lapangan.
\end{abstract}

Kata kunci: industri perkapalan Indonesia, kolaborasi, galangan kapal

\section{Pendahuluan}

Industri perkapalan Indonesia memainkan peranan penting dalam pengembangan perekonomian Indonesia. Sebagai negara kepulauan terbesar dengan jumlah pulaunya mencapai 17.504 pulau dan dengan luas area lautnya kurang lebih sepertiga dari luas Indonesia [1] menjadikan laut sebagai area dengan potensi eksploitasi sumber daya laut yang sangat besar. Untuk mendukung eksploitasi ini 
dibutuhkan kapal laut yang selain berfungsi sebagai sarana eksploitasi sumber daya laut tetapi juga berfungsi sebagai sarana transportasi yang menghubungkan antara satu pulau dengan pulau lainnya. Disinilah industri perkapalan Indonesia memainkan peranan yang sangat penting dalam membangun berbagai kapal yang dibutuhkan itu.

Salah satu bagian dalam industri ini adalah galangan kapal Indonesia. Dengan jumlah galangan kapal yang mencapai 250 galangan [2] dengan berbagai kapasitas pembangunan kapalnya seharusnya menjadi alasan yang kuat untuk tidak memesan kapal baru di galangan kapal luar negeri untuk memenuhi kebutuhan akan kapal laut yang beroperasi dalam wilayah perairan Indonesia. Dukungan pemerintah dengan berbagai kebijakannya untuk mewujudkan ketahanan kapal untuk kebutuhan dalam negeri ini sangat dibutuhkan sehingga kita tidak perlu lagi mengimpor kapal yang akan beroperasi di wilayah perairan Indonesia.

Dalam skala global, galangan kapal dalam negeri belum dapat bersaing secara ketat dengan market share yang kurang lebih 1.6\% dari kapasitas pesanan kapal dunia yang bisa dibangun [3]. Salah satu alasan yang menjadi penyebabnya adalah belum terintegrasinya galangan kapal dalam negeri sehingga total kapasitas galangan dalam negeri sangat jauh dari beberapa galangan kapal dunia yang menguasai hampir 90\% dari total kapasitas pesanan kapal dunia [4].

Sekarang ini, kecenderungan persaingan galangan kapal dunia dalam mendapatkan pesanan kapal adalah bukan lagi antar galangan kapal secara individual tetapi sudah bergeser ke persaingan galangan kapal dalam sebuah kolaborasi. Jika hal ini tidak direspons secara cepat oleh galangan kapal dalam negeri, maka bisa terjadi, market share pembangunan kapal pesanan luar negeri oleh galangan kapal dalam negeri akan terus menurun. Karenanya, sangat penting bagi galangan kapal dalam negeri untuk tetap berdaya saing dan bertahan dalam era global yang sangat dinamis dan menantang ini.

Daya saing galangan kapal dalam negeri dalam lingkungan global sekarang ini harus ditingkatkan. Firmansyah and Amer [5] menjelaskan bahwa terdapat beberapa faktor yang menghambat sebuah perusahaan termasuk galangan kapal untuk secara penuh mengambil manfaat yang besar dari keterbukaan lingkungan bisnis global ini. Namun faktor utama yang bisa disimpulkan dari penjelasan itu dan menjadi masalah utama adalah kekurangmampuan perusahaan itu untuk melakukan kolaborasi baik dengan perusahaan domestik maupun dengan perusahaan dari luar negeri.

Karena lingkungan bisnis galangan kapal sekarang ini terindikasi dengan trend kolaborasi dan jaringan integrasi antar galangan, maka galangan kapal dalam negeri juga harus terlibat dalam sebuah kolaborasi atau jaringan integrasi antar galangan. Jika tidak demikian, maka galangan kapal dalam negeri akan sulit untuk menghasilkan dan menyerahkan produk kapal pada tempat, waktu dan harga yang ditetapkan. Tidak ada galangan kapal di manapun bahkan dengan sumber daya yang berlimpah bisa memproduksi dan menangani sekian banyak proyek pembangunan kapal sendiri. Hal ini dibatasi oleh kapasitas galangan itu sendiri sehingga jika ingin memperbesar kapasitas pembangunan kapal, sebuah galangan kapal harus berkolaborasi atau terlibat dalam sebuah jaringan kerja antar galangan. PT PAL mungkin dapat dijadikan contoh kasus ini, beberapa tahun lalu, PT PAL harus menolak sebuah proyek pembangunan kapal senilai 500 juta dollar karena kapasitas galangan yang sudah tidak memungkinkan [6]. Penolakan ini bisa dihindari jika PT PAL pada saat itu telah bergabung dalam sebuah kolaborasi dengan beberapa galangan kapal dalam negeri. Dengan demikian, kapasitas galangan akan meningkat dan PT PAL tetap dapat memenuhi pesanan itu dengan sub kontrakkan beberapa blok kapal dan kemudian dilakukan pekerjaan erection di PT PAL. Sehingga sangat penting sekarang ini bagi 
sebuah perusahaan termasuk galangan kapal untuk terlibat dalam sebuah kolaborasi [7].

Keterlibatan galangan kapal dalam negeri dalam sebuah jaringan kolaborasi akan mencegahnya terhadap dampak fluktuasi dinamika pembangunan kapal dan pada saat yang sama akan meningkatkan daya saing dan market share-nya. Namun sayangnya, belum ada sebuah model jaringan kolaborasi yang tepat bagi galangan kapal dalam negeri yang sesuai dengan karakteristik dan kondisi galangan kapal dalam negeri [5].

Institusi pendidikan dan lembaga penelitian dalam bidang kemaritiman di Indonesia memegang peranan yang sangat penting dalam membantu memecahkan permasalahan yang dihadapi oleh galangan kapal dalam negeri ini. Dukungannya dapat dalam bentuk bantuan pengetahuan berupa design model yang sesuai untuk integrasi galangan kapal dalam negeri Indonesia. Model ini harus didesain dengan memerhatikan karakteristik, kapabilitas dan kondisi galangan kapal dalam negeri. Model ini juga harus dapat memperkuat kapasitas kemampuan daya saing secara keseluruhan galangan kapal anggotanya. Sebagai langkah awal, sebuah model awal integrasi galangan kapal dalam negeri telah dikembangkan oleh Firmansyah, et al. [8] dengan memerhatikan karakteristik dari galangan kapal Indonesia seperti yang dijelaskan sebelum ini.

Tujuan dari paper ini adalah untuk menekankan karakteristik galangan kapal dalam negeri akan pentingnya sebuah model integrasi galangan kapal dalam negeri seperti yang telah mulai dikembangkan oleh Firmansyah, et al. [8] dan tantangan yang akan dihadapi dalam proses implementasi model seperti ini di lapangan. Berdasarkan hal itu, paper ini akan disajikan sebagai berikut: yang pertama, akan ditinjau beberapa model jaringan kolaborasi, kemudian akan di diskusikan model yang sesuai untuk galangan kapal Indonesia. Setelah itu, dijelaskan kesesuaian sebuah model awal integrasi untuk galangan kapal dalam negeri yang telah dikembangkan oleh Firmansyah, et al. [8]. Pada model awal ini, hanya dilibatkan 4 buah galangan kapal dalam negeri yang berada dalam koordinasi Kementrian BUMN yaitu galangan kapal PT Penataran Angkatan Laut (PAL), galangan kapal PT Dok dan Perkapalan Surabaya (DPS), galangan kapal PT Dok Kodja Bahari (DKB) dan terakhir galangan kapal PT Industri Kapal Indonesia (IKI). Dibagian akhir, tantangan yang dihadapi dalam implementasi model awal ini akan dijelaskan.

\section{Tinjauan Beberapa Model Jaringan Kolaborasi}

Terdapat beberapa macam model kolaborasi yang telah dikembangkan oleh beberapa peneliti. Pembagian model kolaborasinya ada yang didasarkan pada tingkat keterlibatan perusahaan dan kedudukan tiap perusahaan pada jaringan kolaborasi itu [9], ada yang mendasarkan pada pembagian zona kolaborasinya [10] dan yang ketiga adalah pembagian yang berdasarkan pada jaringan produksi kolaborasinya dan pada perusahaan apa yang menggerakkan jaringan [11]. Pembagian model kolaborasi berdasarkan tingkat keterlibatan perusahaan dapat dibagi secara umum kedalam tiga bentuk model kolaborasi. Yang pertama adalah bentuk kolaborasi antara sebuah perusahaan besar sebagai kontraktor utama dan beberapa perusahaan yang lebih kecil sebagai sub kontraktor. Kontraktor utama yang menerima order pembuatan produk sedangkan subkontraktor yang menyuplai produk antara (interim product) kepada kontraktor utama. Yang kedua adalah bentuk kolaborasi yang dilakukan oleh beberapa perusahaan dengan persamaan kedudukan diantara mereka dan di mana tidak terdapat 
sebuah perusahaan yang terlihat sangat menonjol dibanding yang lain. Yang terakhir adalah bentuk kolaborasi di mana perusahaan kecil tetap terlibat dalam sebuah jaringan kolaborasi dengan beberapa supplier namun mereka yang langsung menjual produk pesanan kepada konsumen. Cakupan kolaborasinya mencakup area yang kecil [9].

Walker [10] membagi kolaborasinya berdasarkan zona jaringan rantai pasoknya yang terdiri dari 4 zona yaitu upstream zona, midstream zona, downstream zona dan reverse zona. Pembagian zona ini didasarkan pada aliran produksi sebuah produk dari supplier bahan mentah yang paling awal hingga produk akhir di serahkan kepada konsumen (upstream hingga downstream zona). Sehingga pada upstream zona, supplier bahan mentah berkolaborasi dengan perusahaan komponen produk, pada midstream zona, perusahaan komponen produk berkolaborasi dengan perusahaan sub assembly atau assembly atau final produk dan terakhir pada downstream zona, perusahaan final produk berkolaborasi dengan distributor, transporter dan retailer untuk menyerahkan final produk ke konsumen. Walker [10] menambahkan zona ke empat (reverse zona) karena ia melihat sebuah rantai pasok proses sebagai sebuah siklus. Pada zona yang terakhir ini, final produk yang telah digunakan oleh konsumen kemudian di manfaatkan lagi bagian bagian produknya yang masih bisa digunakan untuk di produksi kembali dan menjadi bagian produk yang lain.

Pada model kolaborasi yang terakhir, Abonyi [11] membaginya berdasarkan pada jaringan yang digerakkan oleh perusahaan pembuat produk (producer), jaringan yang digerakkan oleh pembeli (buyer), dan jaringan yang digerakkan oleh baik producer maupun buyer (hybrid network). Pada jaringan pertama, perusahaan pembuat produk yang menentukan produk standar dan spesifikasinya, pada jaringan kedua, justru pembeli dalam hal ini retailer atau konsumen langsung yang menentukan produk standar dan spesifikasinya, sedangkan pada jaringan ketiga yang merupakan kombinasi dari jaringan pertama dan kedua, produk standar dan spesifikasinya ditentukan oleh baik pembuat produk maupun pembeli. Karena pada jaringan terakhir ini masingmasing mempunyai kedudukan yang sama, maka baik pembuat maupun pembeli akan menentukan produk standar yang relative berbeda.

\section{Model yang sesuai untuk galangan kapal Indonesia}

Galangan kapal adalah sebuah perusahaan di mana kapal dibangun dan diperbaiki. Tidak seperti umumnya perusahaan lain yang memproduksi produk kemudian dijual (Made To Stock), galangan kapal seperti perusahaan konstruksi lain adalah perusahaan yang bercirikan Made To Order [12]. Ini berarti kapal baru akan dibangun jika ada pesanan dari Owner untuk membangun kapal sesuai dengan spesifikasi yang ditetapkannya. Berdasarkan karakteristiknya ini maka sebuah model kolaborasi yang dijelaskan sebelum ini tidak sesuai untuk diterapkan pada perusahaan galangan kapal tetapi harus kombinasi dari beberapa model jaringan kolaborasi.

Galangan kapal adalah sebuah perusahaan yang karakteristik dan spesifikasi produk akhirnya (kapal) ditentukan oleh pembeli (Abonyi [11] model). Dalam proses konstruksinya, sebuah galangan kapal yang mendapatkan pesanan pembuatan kapal umumnya melibatkan subkontraktor untuk merangkai bagian bagian dari kapal itu (Shinawatra [9] model). Namun umumnya pekerjaan subkontraktornya dilakukan pada galangan yang bersangkutan dengan memanfaatkan fasilitas di galangan itu. Komponen komponen bagian kapal dibeli dari beberapa supplier langganan galangan itu dan kemudian dirangkai menjadi blok dan kapal sebagai produk akhir (Walker [10] model). 
Model jaringan kolaborasi yang tepat bagi galangan kapal kemudian adalah model yang dapat mengakomodasi karakteristik dari galangan kapal itu yang merupakan kombinasi dari beberapa model jaringan kolaborasi seperti yang dijelaskan pada bagian sebelum ini. Selain itu harus dilakukan perluasan dari gabungan model jaringan kolaborasi yang ada sehingga bisa menggantikan peran sub kontraktor dari perusahaan bukan galangan kapal menjadi perusahaan galangan kapal. Jaringan rantai supply juga sudah harus dimasukkan dalam model jaringan kolaborasi yang akan dikembangkan yang berawal dari supplier bahan mentah hingga distributor atau transporter agar terjamin proses produksi dan penyerahan produk akhir.

\section{Model awal integrasi untuk galangan kapal di Indonesia}

Berdasarkan persyaratan yang disebutkan sebelumnya, Firmansyah, et al. [8] telah mengembangkan sebuah model awal untuk integrasi industri pembangunan kapal di Indonesia. Pada model awal ini, baru 4 galangan kapal dalam negeri milik Badan Usaha Milik Negara (BUMN) yang diintegrasikan yaitu galangan kapal PT PAL Surabaya, galangan kapal PT Dok dan Perkapalan Surabaya (DPS), galangan kapal PT Dok Kodja Bahari (DKB) dan galangan kapal PT Industri Kapal Indonesia (IKI). Tujuan dari integrasi keempat galangan kapal ini adalah untuk meningkatkan kapasitas keseluruhan dari galangan kapal BUMN selain untuk meningkatkan kemampuan daya saingnya di dunia internasional.

Pada model awal ini, galangan BUMN itu saling membagi sumber daya dan fasilitas mereka. Sedangkan untuk kepentingan pembangunan kapalnya, beberapa supplier komponen kapal dihubungkan ke semua galangan kapal peserta sehingga setiap galangan peserta akan mendapatkan suplai bahan baku, dan komponen kapal yang sama dari sumber supplier yang sama (lihat Gambar 1).

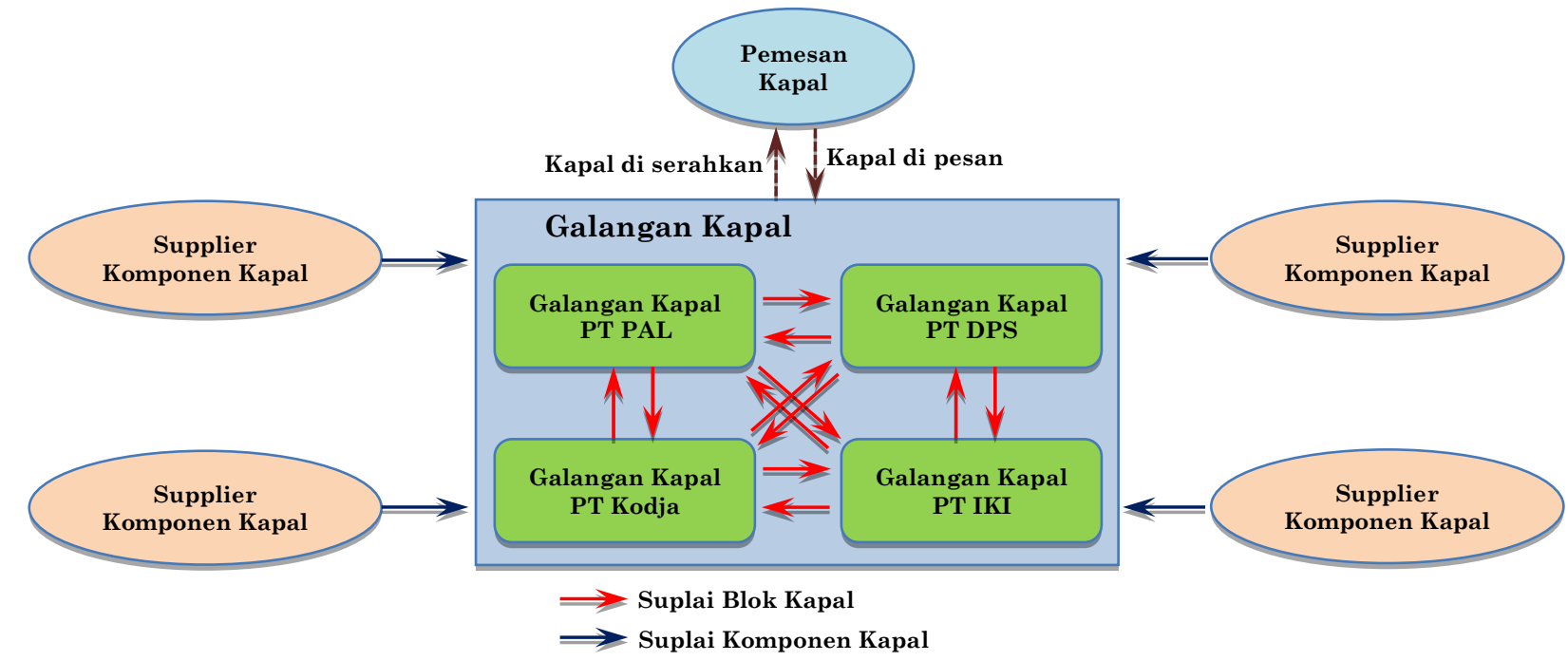

Gambar 1 Model awal integrasi galangan kapal BUMN [12]

Terdapat 4 skenario yang bisa terjadi pada model integrasi ini di mana dasar skenarionya adalah kemampuan setiap galangan kapal untuk membangun ukuran kapal tertentu dan pada galangan kapal mana yang mendapatkan order pesanan kapal. Berdasarkan hal itu, paling tidak satu atau lebih galangan dalam model ini akan menjadi kontraktor utama yang akan membangun sebagian blok kapal dan melakukan proses erection blok kapal sedangkan galangan kapal lain akan menjadi sub kontraktor 
yang akan membangun blok kapal yang lain dan kemudian menyuplai blok itu ke kontraktor utama.

Karena setiap galangan BUMN mempunyai kapasitas pembangunan kapal baru yang berbeda satu sama lain, maka bergantung pada dimensi kapal yang akan dibangun, penentuan galangan kapal yang akan menjadi kontraktor utama juga bergantung pada hal itu. Ukuran kapal terbesar yang bisa dibangun dalam jaringan kolaborasi galangan kapal BUMN ini adalah 50.000 DWT sesuai dengan kapasitas maksimum dari PT PAL.

Jika diurutkan kapasitas pembangunan kapal dari keempat galangan BUMN, maka PT PAL akan berada di urutan teratas dengan kapasitas maksimum 50.000 DWT diikuti oleh PT Kodja Bahari, PT DPS dan PT IKI dengan masing-masing kapasitas maksimum pembangunan kapalnya adalah 17.500 DWT, 8.000 DWT dan 4.000 DWT.

Berdasarkan pada kapasitas maksimum masing-masing galangan ini, skenario pembangunan kapalnya kemudian dapat didasarkan pada besaran kapasitas kapal yang dipesan. Yang pertama adalah pesanan pembangunan kapal dengan range kapasitas 17.500 DWT hingga 50.000 DWT (skenario 1), yang kedua adalah dari range 8.000 DWT hingga 17.500 DWT (skenario 2), yang ketiga adalah dari range 4.000 DWT hingga 8.000 DWT (skenario 3) dan yang terakhir adalah range di bawah 4.000 DWT (skenario 4). Yang menjadi kontraktor utama dalam pembangunan pesanan kapal itu disesuaikan dengan kapasitas pembangunan masing-masing galangan.

Jika ada lebih dari satu galangan yang dapat menjadi kontraktor utama, maka penentuan galangan kapal yang menjadi kontraktor utama adalah pada galangan yang mendapatkan order pesanan pembangunan kapal itu. Bergantung pada jumlah kapal yang akan dibangun, master schedule pembangunan kapal sepenuhnya akan ditentukan oleh galangan kapal itu.

Dasar utama desain model awal jaringan integrasi antar galangan BUMN ini adalah penolakan pesanan pembangunan kapal oleh galangan kapal PT PAL beberapa tahun lalu senilai kurang lebih 500 juta US dollar akibat ketidakmampuan kapasitas galangan pada saat itu yang sedang mengerjakan banyak proyek. Jika pada saat itu, telah dibentuk jaringan integrasi antar galangan BUMN, maka pesanan pembangunan kapal itu dapat diterima dengan model pembangunan kapal yang membagi sebagian besar pembangunan blok kapal ke galangan BUMN yang lain dan kemudian proses erection kapal dilakukan di PT PAL. Detail penjelasan tentang model integrasi awal ini dapat dirujuk pada paper yang ditulis oleh Firmansyah, et al. [8].

\section{Tantangan dalam implementasi model awal integrasi}

Model awal seperti yang dikembangkan oleh Firmansyah, et al. [8] di atas membutuhkan banyak persyaratan persyaratan yang harus dipenuhi oleh setiap galangan peserta demi keberhasilan prosesnya sebelum model itu dapat dilaksanakan. Persyaratan persyaratannya menjadi tantangan tersendiri bagi setiap galangan untuk dipenuhi demi meningkatkan kapasitas bersama dan kemampuan daya saingnya di dunia internasional.

Pada dasarnya, setiap galangan kapal yang menjadi peserta dalam model integrasi ini harus melakukan pembenahan internal galangannya masing masing. Pembenahan ini harus merujuk pada galangan kapal terbaik dan menjadi benchmarking dalam model integrasi ini. Indikator yang bisa menjadi acuan adalah kesamaan dalam tingkatan penggunaan teknologi produksi kapal. Audit teknologi dapat digunakan sebagai tool untuk mengukur tingkatan teknologi produksi kapal setiap galangan peserta dalam model ini [13]. Selain itu, sebuah standar akan tingkatan 
accuracy control $(A / C)$ perlu disepakati secara bersama sehingga setiap galangan kapal akan tahu tingkatan accuracy control ketika menerima blok kapal dari galangan lain [14]. Hal lain yang tidak kalah pentingnya adalah adanya kepercayaan (trust) yang penuh akan jaminan kerahasiaan akan data yang akan di share kepada sesama galangan dalam model ini [15]. Terakhir dan yang paling penting dalam model jaringan integrasi ini dan juga pada model model yang lain adalah adanya komitmen penuh dari top manajemen untuk melaksanakan semua persyaratan dan kesepakatan yang dibuat dalam model ini [16]. Informasi lebih detail untuk setiap persyaratan itu akan dijelaskan pada sub bagian berikut ini.

\subsection{Audit Teknologi}

Audit teknologi adalah sebuah tool yang efektif yang pertama kali diperkenalkan oleh Birmingham, et al. [17] untuk mengukur tingkatan teknologi yang digunakan oleh sebuah galangan kapal. Audit teknologi ini tidak mengukur kinerja aktual galangan melainkan potensi kemampuan galangan itu dari penggunaan teknologi produksi kapalnya. Audit ini mengukur serangkaian elemen teknologi di sebuah galangan baik itu yang berkaitan dengan teknologi perangkat keras maupun teknologi perangkat lunak yang digunakan di galangan itu. Hasil dari audit ini akan dapat menentukan kemampuan teknologi produksi galangan yang di rating dalam lima tingkatan teknologi produksi kapal. Hasil audit bisa direpresentasikan dalam sebuah tingkatan teknologi secara keseluruhan atau untuk setiap elemen teknologi yang di audit [17].

Setiap galangan yang terlibat dalam model integrasi ini harus melakukan audit teknologi agar dapat diketahui tingkatan teknologi untuk setiap elemen teknologi serta keseluruhan galangan. Perbedaan dalam tingkatan teknologi keseluruhan maupun pada elemen teknologi setiap galangan dapat menyebabkan perbedaan kemampuan pengerjaan komponen dan blok kapal. Untuk menyamakannya sehingga setiap galangan mempunyai tingkatan elemen teknologi dan tingkatan keseluruhan galangan yang relatif sama, maka perlu dilakukan alih teknologi dari galangan peserta dengan tingkatan teknologi yang lebih tinggi ke galangan dengan tingkatan teknologi yang lebih rendah (lihat Gambar 2) [13].

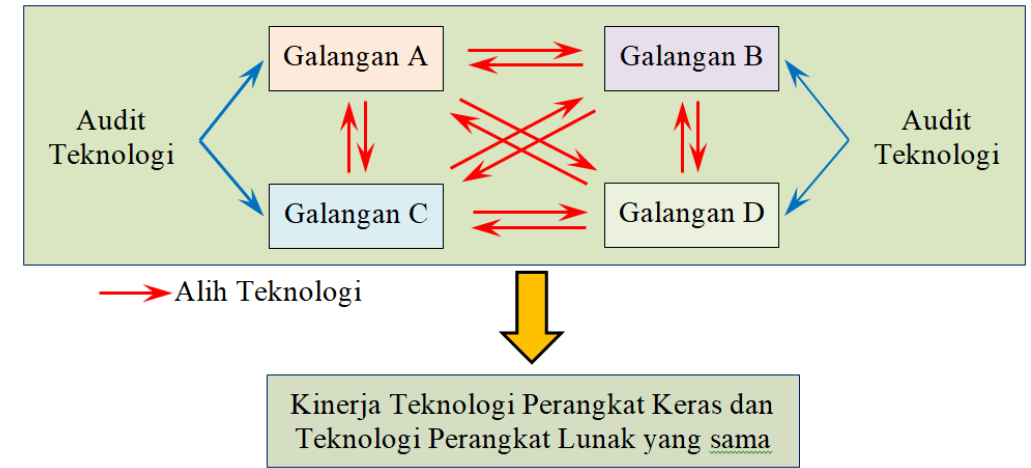

Gambar 2 Penyamaan kinerja teknologi perangkat keras dan teknologi perangkat lunak galangan

\subsection{Standar Pengendalian Akurasi (Accuracy Control - A/C)}

Standar system accuracy control juga harus disepakati bersama. Tujuannya adalah menjamin kualitas produk baik produk antara (interim product) maupun produk akhir secara kuantitatif dan kualitatif. Secara bersama sama, semua galangan kapal 
yang terintegrasi dalam model ini merumuskan, merevisi, menetapkan dan kemudian menerapkan standar system accuracy control yang disepakati bersama. Dalam kaitannya dengan penerapan standar A/C ini, setiap galangan harus melakukan pembenahan untuk setiap aspek pendukung penerapan standar $\mathrm{A} / \mathrm{C}$ ini antara lain sumber daya manusia, peralatan, material dan metode kerja [14].

Sumber daya manusia galangan sebagai pelaksana penerapan standar A/C ini perlu untuk ditingkatkan keterampilan, motivasi, tanggung jawab, disiplin, rasa memiliki, kreatifitas dan kemampuan manajerialnya. Untuk tenaga kerja produksi langsung, mereka disyaratkan untuk menerapkan system $\mathrm{A} / \mathrm{C}$ yang direncanakan dan kemudian melakukan self checking terhadap hasil kerjanya. Selain itu, tenaga kerja yang bertugas melakukan proses evaluasi dan analisis data hasil pengukuran dan penyempurnaan detail desain dan petunjuk kerjanya juga perlu memiliki kualifikasi yang tinggi [18].

Mesin mesin produksi yang melakukan proses secara langsung terhadap material atau produk antara (interim product) perlu untuk dipertahankan konsistensi kerjanya dan secara reguler melakukan kalibrasi terhadap mesin mesin itu. Mesin mesin produksi itu harus diidentifikasi dan dikelompokkan menurut jenis mesin, karakteristik operasi dan data operasi mesin lainnya. Pengaruh operasi setiap mesin terhadap bentuk dan dimensi produk yang dihasilkan juga harus diketahui dan didokumentasikan [18].

Material yang digunakan dalam pembangunan kapal cenderung mengalami perubahan dimensi akibat perlakuan selama proses produksi. Perubahan dan kemungkinan penyimpangan ini harus diketahui dan dijadikan pertimbangan untuk penyempurnaan gambar gambar kerja dan petunjuk petunjuk produksinya. Sifat mekanis material yang digunakan harus menjadi pertimbangan dalam pemberian margin (toleransi) untuk setiap material yang akan diproses. Penyimpangan dimensi diluar toleransi pada suatu proses produksi akan menyebabkan penyimpangan dalam bentuk dua maupun tiga dimensi pada saat penyambungan blok di galangan lain [18].

Jika ketiga aspek diatas telah dibenahi, maka metode kerja untuk setiap proses produksi yang dibuat pada tahapan desain dengan memerhatikan umpan balik (feedback) dari produksi harus dilakukan secara konsisten [18].

\subsection{Kepercayaan (trust) dan komitmen manajemen puncak}

Interaksi antar galangan dalam model jaringan integrasi ini melibatkan pertukaran informasi dan data yang dibutuhkan. Dalam proses interaksinya ini, perlu dibangun sebuah kepercayaan (trust) dan jaminan dari setiap galangan bahwa data dan informasi yang dipertukarkan itu akan tetap terjamin kerahasiaannya diantara sesama galangan dalam model jaringan kolaborasi ini.

Kepercayaan sangat penting dalam membangun hubungan kerja sama jangka panjang dalam sebuah jaringan kolaborasi yang berhasil [19]. Hal ini bisa dicapai dengan membagi (sharing) nilai nilai, menjalin komunikasi yang efektif dan menghindari perilaku oportunistic [20]. Hubungan yang baik hanya bisa dicapai pada sebuah kolaborasi yang baik. Perilaku anggota dalam sebuah kolaborasi dipengaruhi oleh seberapa besar tingkat kepercayaan setiap anggota terhadap kolaborasi yang ada. Selain itu, kepercayaan yang dibangun dalam sebuah jaringan kolaborasi akan memengaruhi tingkatan pertukaran informasi antar perusahaan [21, 22]. Sehingga dalam model jaringan kolaborasi ini, kepercayaan dari setiap anggota harus di bangun dengan transparansi proses yang terjadi dalam model [23].

Komitmen dari manajemen puncak sangat berperan penting dalam keberhasilan dan kegagalan membangun kepercayaan dalam tahapan implementasi [16] dan [20] 
bukan saja dalam tataran jaringan kolabarasi antar perusahaan bahkan dalam hubungan perdagangan antar negara juga sangat penting [24].

\section{Simpulan}

Salah satu cara untuk meningkatkan kapasitas sekaligus daya saing galangan kapal di Indonesia adalah dengan membentuk atau tergabung dalam sebuah jaringan kolaborasi. Pada paper ini, telah dibahas beberapa model jaringan kolaborasi yang telah diterapkan oleh beberapa perusahaan dan kemudian dilanjutkan dengan tinjauan model model itu terhadap kesesuaiannya dengan sebuah jaringan kolaborasi antar galangan kapal di Indonesia. Setelah itu sebuah model awal integrasi yang dikembangkan oleh Firmansyah, et al. [8] dari 4 galangan kapal di Indonesia yang berada di bawah Kementrian Badan Usaha Milik Negara dibahas. Namun, dalam pelaksanaan model awal ini nantinya, akan ditemui beberapa hal yang dapat mencegah jaringan kolaborasi ini untuk terlaksana. Olehnya, beberapa hal yang menjadi tantangan dalam penerapan model awal ini dibahas lebih detail diantaranya adalah perlunya melakukan audit teknologi untuk semua galangan yang terlibat dalam model ini dan alih teknologi dari galangan kapal dengan kinerja teknologi perangkat keras dan teknologi perangkat lunaknya yang lebih baik ke galangan kapal dengan kinerja teknologi perangkat keras dan teknologi perangkat lunaknya yang lebih rendah. Selain itu, perlu menetapkan sebuah standar untuk Accuracy Control $(A / C)$ yang harus diterapkan oleh semua galangan. Tantangan terakhir yang tidak kalah pentingnya adalah perlunya membangun kepercayaan diantara galangan kapal dalam model ini agar proses interaksi informasi dan data diantara galangan kapal dapat terjalin dengan baik. Peran dalam bentuk komitmen dari manajemen puncak diperlukan dalam hal ini agar keberhasilan dalam tahapan pelaksanaannya dapat dicapai.

\section{Referensi}

[1] B. P. Statistik. (2002-2015, 10/12/2017). Luas Daerah dan Jumlah Pulau Menurut Provinsi. Available: https://www.bps.go.id/index.php/linkTabelStatis/1366

[2] W. Edi, "Industri Galangan Kapal Nasional dalam Mendukung Program Tol Laut," presented at the Kongres Infrastruktur Maritim 9 Agustus 2017 di Makassar, 2017.

[3] W. Djafar, "Indonesian Shipbuilding Industry in the perspective of Collaborative Manufacturing Network (CMN)," International Journal of Engineering and Science Applications, vol. 3, pp. 161-167, 2017.

[4] NA. (2017, 30 September 2017). Shipbuilding Statistics. Available: https://www.sajn.or.jp/files/view/articles_doc/src/73265e1329b4a8e0ae4fe4bcf31c7 e5b.pdf

[5] M. R. Firmansyah and Y. Amer, "A review of collaborative manufacturing network models," Int. J. Mater. Mech. Manufact, vol. 1, pp. 6-12, 2013.

[6] Zuhal, Kekuatan Daya Saing Indonesia, Mempersiapkan Masyarakat Berbasis Pengetahuan. Jakarta: Penerbit Buku Kompas, 2008.

[7] N. Conradsen and M. Lystlund, "The vision of next generation manufacturinghow a company can start," Integrated Manufacturing Systems, vol. 14, pp. 324333, 2003.

[8] M. R. Firmansyah, W. Djafar, and A. H. Muhammad, "Initial Model Development of an Integrated Shipbuilding Industry in Indonesia: a Case Study of Indonesian 
State Owned Enterprises (BUMN) Shipyards," International Journal of Engineering and Science Applications, vol. 4, pp. 183-190, 2018.

[9] T. Shinawatra, "The importance of improving SME value chains," in Proceedings of the APEC SME 2001 Conference on Strategic Alliances for Efficient Supply Chain Management, 2001, pp. 1-2.

[10] W. T. Walker, Supply chain architecture: a blueprint for networking the flow of material, information, and cash: CrC Press, 2016.

[11] G. Abonyi, "Integrating SMEs into global and regional value chains: implications for subregional cooperation in the Greater Mekong Sub region," UNESCAP: Bangkok, 2005.

[12] K.-H. Chang and Y.-S. Lu, "Queueing analysis on a single-station make-tostock/make-to-order inventory-production system," Applied Mathematical Modelling, vol. 34, pp. 978-991, 2010.

[13] M. Firmansyah and W. Djafar, "Conceptual Model for Transfer of Technology in a Shipyard," International Journal of Engineering and Science Applications, vol. 4, pp. 43-50, 2017.

[14] E. Paul, D. E. Babu, and B. Paul, "Design of an Accuracy Control System in Ship Building Industry."

[15] M. Danilovic and M. Winroth, "A tentative framework for analyzing integration in collaborative manufacturing network settings: a case study," Journal of Engineering and Technology Management, vol. 22, pp. 141-158, 2005.

[16] N. Clarke, "The relationships between network commitment, its antecedents and network performance," Management Decision, vol. 44, pp. 1183-1205, 2006.

[17] R. Birmingham, S. Hall, and R. Kattan, "Shipyard technology development strategies," Journal of Ship production, 1997.

[18] R. L. Storch, "Accuracy control implementation manual," Shipyard Production Process Technologies Panel, NSRP, vol. 314, p. 21, 2002.

[19] B. B. Nielsen, "The role of trust in collaborative relationships: A multidimensional approach," M@n@gement, vol. 7,pp. 239-256, 2004.

[20] S. J. Zlatkovic, "Success Factors in Building and Maintaining Trust Among Globally Distributed Team Members," ed, 2009.

[21] J. T. Murphy, "Networks, trust, and innovation in Tanzania's manufacturing sector," World development, vol. 30, pp. 591-619, 2002.

[22] C. Tomkins, "Interdependencies, trust and information in relationships, alliances and networks," Accounting, organizations and society, vol. 26, pp. 161-191, 2001.

[23] S. M. Kac, I. Gorenak, and V. Potocan, "The influence of trust on collaborative relationships in supply chains," E+ M Ekonomie a Management, vol. 19, p. 120, 2016.

[24] C. Bianchi and A. Saleh, "On importer trust and commitment: a comparative study of two developing countries," International Marketing Review, vol. 27, pp. $55-86,2010$. 